\title{
Introduction: \\ Elites and their Representation: Multi-Disciplinary Perspectives
}

\author{
Jean-Pascal Daloz
}

The term "elite" was introduced in the seventeenth century to describe commodities of an exceptional standard and the usage was later extended to designate social groups at the apex of societies. The study of these groups was established as part of the social sciences in the late nineteenth century, mainly as a result of the work of three sociologists: Vilfredo Pareto, Gaetano Mosca and Roberto Michels. The core of their doctrine is that at the top of every society lies, inevitably, a small minority which holds power, controls the key resources and makes the major decisions. Since then, the concept of elite(s) has been used in several disciplines such as anthropology, history or political science, but not necessarily in reference to this "classical elite theory." The concept is strongly rejected, however, by many "progressive" scholars-precisely because of its elitist denotation.

A major difficulty arises from the fact that it is frequently related to normative discourses, either positive or negative. Elites have thus been regarded as either the integrating force in society or as a parasitic nuisance that may lead to its ruin. For some, they should be seen as the guarantors of pluralism and as a safeguard against totalitarianism, whereas for others they represent a major threat to democracy. ${ }^{1}$ Consequently, much of the work on those men and women who hold a dominant, or commanding, place in society has been biased by predisposed assessments, rather than concerned with analytical perspectives. It is nevertheless quite possible to consider elites as a significant object of scholarly attention without any evaluative implications whatsoever.

Like many others in the social sciences and humanities, the concept of elite(s) has heuristic advantages and disadvantages. Its principal merit is that it subsumes all sorts of upper groups, including in those contexts where the concept of class would seem inappropriate. However, such breadth is also liable to be viewed as an inconvenience, in so far as the bringing together of members from disparate sectors potentially entails a certain degree of im- 
precision. Specialists are often asked how they define elites and which type of people they actually refer to when they use the term. To answer such questions is not as easy as it might seem because configurations can be, objectively and subjectively, quite different from one country to another. For instance, we may be dealing with a monolithic elite or with a plurality of sub-groups controlling various sectors-hence some hesitations over the use of the singular or the plural. A movie star, a singer or a sports celebrity may be part of the elite, thanks to their fame and high income, or they may be more or less rejected because such activities are regarded as "trivial." It is also interesting to note that the denomination immediately makes sense in many countries, whereas in some others (e.g. in Scandinavia) upper-level actors do not feel comfortable with it. Similarly, it is undoubtedly difficult to conceive of a "horrible" dictator as belonging to the category of elites when one has the above-mentioned "excellence" dimension in mind.

Another major advantage of an approach in terms of elites is that its object is quite concrete. In contrast to many analyses which are all too often conducted at an excessively abstract level, this approach is obviously centered on actors. One may endlessly wallow in rather sterile discussions about the nature of "the state," for instance, but things become much less elusive when researchers look into the actual behavior of real persons at the top of such institutions. It should be added that studies on elites commonly lead to realist, as opposed to idealist, conceptions. If we return to the classics, one may consider that an author such as Pareto (who was very much concerned with refuting Marx) developed a vision of society and politics which is not so far removed from a Marxist one, in that everything is uncompromisingly analyzed in terms of power struggles or mystifying ideologies (in his words "derivations"). However, he differed crucially from Marx when he stated that the domination of elites was inexorable, including in those systems claiming to promote equality.

This does not mean that one should blindly adhere to elite theory. Even the proponents of this school of thought felt obliged to restate their premises to some extent, especially regarding relationships with non-elites. ${ }^{2}$ This revision, sometimes referred to as "neo-elitism," pays much more attention to the somewhat unprecedented position of elites within modern democratic settings. It had to be admitted that even if elites are never simply the puppet of larger forces or structures, they are seldom wholly independent actors either. Moreover, it is particularly fascinating from a comparative point of view to show how elites may indeed be constrained by the cultural environment they share on a societal level. Quite often it is therefore necessary to distance oneself from a Machiavellian vision in terms of purely manipulative elites. ${ }^{3}$

Most analytical studies tend to concentrate on recurrent questions such as the accumulation of resources, the recruitment of elites, or their power structure. ${ }^{4}$ It is important to note that certain themes remain durably controversial. For example, some authors are keen to stress the importance of social reproduction processes whereas others emphasize the "circulation" 
of elites. Likewise, the literature often tends to present elites as a cohesive self-conscious minority. However, the belief in the tendency for power to be concentrated has not gone unchallenged. On the contrary, it is sometimes claimed that in contemporary societies it has become more and more diffused, following a general process of specialization. In this regard, specialists in the United States have long been divided over an ongoing debate about the character of the elite system. In his famous book, The Power Elite, published in 1956, C. Wright Mills described the interconnections between top politicians, owners of large business corporations and the military hierarchy. Later on, Robert Dahl, in his equally famous study of politics in the city of New Haven, showed how no dominant group was able to rule the community. He demonstrated historically how power was dispersed in response to the diversification of interest groups and political resources. ${ }^{5}$ Debates between interpretations in terms of "power elite" or "pluralist elitism" have re-surfaced with regard to the nature of the George W. Bush administration. The situation is similar in France or in the United Kingdom, where scholars endlessly disagree about the existence of a "ruling class" or a so-called "establishment." It is probably judicious, however, to avoid dogmatic reasoning and perceive configurations as diverse and varying considerably over time. ${ }^{6}$

In this respect, it goes without saying that historians have been essential to the field. Experts in various periods and countries have produced quite outstanding contributions that have led to the formulation of a broad range of highly pertinent questions. ${ }^{7}$ They sometimes apply, or at least invoke, general theories which have received acclaim, but this is not systematically the case. In any event, the historical literature helps us to prevent excessively reductionist views. One of our primary tasks should therefore be to build bridges between various currents of elite analysis and the insightful contributions by scholars from different disciplines. ${ }^{8}$

The workshop from which the present collection is drawn was set up with the precise intention of bringing together specialists of several types of elites (political, economic, scientific, and professional). The majority of the contributors are historians; some, however, bring another disciplinary perspective (e.g. sociological or ethnological) to the discussion, but they also share a strong interest in historical perspectives. The meeting took place at the Maison Française d'Oxford in October 2008. ${ }^{9}$ The aim of this workshop, which Muriel Le Roux and I had the pleasure to co-organize, was to compare and contrast our research experiences, and focusing on key dynamics as well as on particular methodological and conceptual issues. The following articles therefore not only deal with various categories of elites but also with different contexts. Although one may not find a particular central strand running throughout the contributions, it is hoped that this collection will offer the reader the range of how contemporary elite studies can provide a better understanding of some revealing aspects.

The first article is by Christophe Charle, a highly reputed specialist in the study of French elites, notably those of the beginning of the Third Republic. 
He encourages us to consider two very crucial themes in elite studies: that of recruitment into elite status and that of the competition between longestablished elites and newcomers. In his contribution to this special issue, he looks at the French case in contrast with the British and German ones. Criticizing Arno Mayer's rather vague categorizations and his claim that European society was a persistent "Old Regime" at the end of the nineteenth century, Christophe Charle argues that this is largely incorrect with respect to the French case. Admittedly, the top positions of certain sectors, such as the military or the diplomatic corps, remained predominantly occupied by members of the aristocracy. Nonetheless, members of the French bourgeoisie did obtain many administrative positions and held much of the social, economic and political power during that period. In France, access to many key institutions had increasingly become a result of education, although we are reminded that the system was still far from being entirely "democratic" at that stage, despite several important reforms.

The piece by Anne Krogstad and Aagoth Storvik, two Norwegian scholars, is also comparative and leads us to contrast the image of male political leaders in France and Norway. Emphasizing changes and continuity since the end of World War II, the two authors suggest that, whereas Norwegian politicians have been traditionally seen as modest and connected to the people, French political elites have often played the card of elegance and seduction. However, the new generation of Norwegian leaders seeks to present itself in a less demure and self-effacing way, which does not mean that these leaders resemble their French colleagues, whose presentation of the self is durably characterized by "effortless superiority." This contribution draws our attention to the importance of cultural as well as gendered repertoires when it comes to studying political elites.

In a most fascinating paper, Justine Rogers introduces us to the very elitist world of the English Bar. More precisely, she analyses the process of selection and socialization of trainee barristers during what is called the "pupillage" phase. For the last thirty years, the Bar has faced a series of challenges to its elite status. The great interest of this ethnographic exploration, which also takes into account important historical evolutions, is to present some insightful reflections about the methodological, and indeed personal, difficulties frequently faced by researchers when confronted with elite groups, especially when participant observation is involved.

Muriel Le Roux presents a pioneering research on what could be called a "scientific elite." Looking at the field of chemistry in France and more precisely the case of the Institut de Chimie des Substances Naturelles, she analyses the complex relationships between the pharmaceutical companies and the scientific community within a French context where research is still largely controlled by the public sphere. The question therefore arises as to which actors are deemed the elite of the profession and according to which criteria? Furthermore, she asks who controls the field and how is it that some actors succeed in maintaining a kind of symbolic superiority over their partners. 
As for Eric Godelier, he deals with entrepreneurial elites and is particularly eager to deconstruct some of the myths often associated with wellknown figures belonging to the category of "globalised businessmen." For instance, he reflects upon some persistent representations in terms of "selfmade-men" starting from scratch and paradoxically obtaining a sense of pride from having failed at school. He explores how the false representations purported to describe the "heroes" within the field are perpetuated in training sessions meant for businessmen-to-be. What appears to be at stake here is the social legitimacy of this type of elite in the eyes of the general public.

The next article, by Claire Zalc, discusses the cases of immigrant small entrepreneurs in France during the interwar period. Although they cannot objectively be considered as belonging to the elite, they have sometimes appeared as extraordinarily successful, at least in the eyes of fellow members from their own community. We are touching here on what appears to be the subjective perceptions of remarkable achievement within otherwise rather "dominated" communities struggling for recognition. The pride to be able to employ others and not to be a wage-earner anymore, to be better integrated, and eventually to acquire French citizenship was a concern for scores of immigrants sharing aspirations toward elevated status. What Claire Zalc describes, however, is the fact that, beyond a few success stories and role models, one can find countless "careers" characterized by a high level of instability and serious difficulties regarding processes of naturalization.

Finally, I personally offer some views from a more symbolic perspective. My own (comparative) research focuses on political representatives' ostentation vs. modesty in contemporary democracies and on the sociology of elite distinction. In my latest book, ${ }^{10} \mathrm{I}$ have sought to provide a systematic discussion on the applicability of the major theoretical frameworks that deal with manifestations of social superiority. My goal has been to underline both the virtues and limitations of the models of interpretation available (from Spencer, Veblen, Weber, and Simmel to Elias, Goffman, Bourdieu, and Baudrillard, among many others) when confronted with empirical realities in a large number of environments. I aim to enlighten students of social distinction about the limited applicability of certain concepts and about the implications of turning to a particular theory. In this article, I am concerned with more thoroughly addressing the question of how historians, confronted with a wide range of cases across time and space, have been using these models-whether convincingly or not.

\section{Notes}

1. For general discussions on these issues, see, e.g., T. B. Bottomore, Elites and Society (New York, 1964); Geraint Parry, Political Elites (New York, 1970); William A. Welsh, Leaders and Elites (New York, 1979); Eva Etzioni-Halevy, The Elite Connection: Problems and Potential of Western Democracy (Cambridge, UK, 1993); John 
Higley and Michael G. Burton, Elite Foundation of Liberal Democracy (Lanham, MD, 2006).

2. See G. Lowell Field and John Higley, Elitism (London, 1980).

3. It should be recalled that Pareto, Mosca and Michels have been called Machiavellians or neo-Machiavellians. See James Burnham, The Machiavellians: Defenders of Freedom (Chicago, 1943).

4. From a political science perspective, cf., e.g. Lester G. Seligman, Recruiting Political Elites (New York, 1971); Robert D. Putnam, The Comparative Study of Political Elites (Englewood Cliffs, NJ, 1976); Sydney Verba et al., Elites and the Idea of Equality: A Comparison of Japan, Sweden and the United States (Cambridge, MA, 1987). From a sociological perspective, see, for instance, R. Tamar Horowitz, "From Elite Fashion to Mass Fashion," Archives Européennes de sociologie 16.2 (1975): 283-95; Francie Ostrower, Why the Healthy Give: The Culture of Elite Philanthropy (Princeton, NJ, 1995).

5. C. Wright Mills, The Power Elite (New York, 1956); Robert Dahl, Who Governs? Democracy and Power in an American City (New Haven, CT and London, 1961).

6. See notably Mattei Dogan, ed., Elite Configurations at the Apex of Power (Leiden and Boston, MA, 2003). Such debates concern many countries: cf., e.g. Albrecht Rothacher, The Japanese Power Elite (Basingstoke, UK, 1993).

7. Cf., for instance, the collection edited by Frederic D. Jaher, The Rich, the Well Born, and the Powerful: Elites and Upper Classes in History (Urbana, IL, 1973) or the following monographs: Judith P. Hallett, Fathers and Daughters in Roman Society: Women and the Elite Family (Princeton, NJ, 1984); George Huppert, Les Bourgeois Gentilshommes: An Essay on the Definition of Elites in Renaissance France (Chicago, 1977); Robert Marsh, The Mandarins: The Circulation of Elites in China 1600-1900 (New York, 1961); Betty G. Farrell, Elite Families: Class and Power in NineteenthCentury Boston (Albany, NY, 1993); Evan Madswey and Stephen White, The Soviet Elite from Lenin to Gorbatchev: The Central Committee and its Members, 1917-1991 (Oxford, 2000), among many other possible examples within the widely dispersed literature.

8. This includes, for instance, anthropology. See, e.g. Cris Shore and Stephen Nugent, eds., Elite Cultures: Anthropological Perspectives (London, 2002); Felix M. and Marie M. Keesing, Elite Communication in Samoa: A Study of Leadership (Stanford, 1956); Abner Cohen, The Politics of Elite Culture: Exploration in the Dramaturgy of Power in a Modern Society (Los Angeles, 1981).

9. I wish to acknowledge the support of the Maison Française d'Oxford and of its Director, Luc Borot, as well as that of the French Ministry of Foreign Affairs and that of the OxPo (Oxford-Sciences Po Paris) network coordinated by Sophie Duchesne, for their much-appreciated contributions at various stages. I would also particularly like to express my gratitude to Linda Mitchell (Professor of History at the University of Missouri-Kansas City) who attended the workshop, made a very interesting presentation (on the rhetorical power of castles in the British Isles in the Norman period) and kindly suggested that the papers should be revised and gathered in a special issue of Historical Reflections on elites. Last but not least, thanks very much to Katharine Throssell for proof-reading some of the papers.

10. Jean-Pascal Daloz, The Sociology of Elite Distinction: From Theoretical to Comparative Perspectives (Basingstoke, UK and New York, 2009). 